
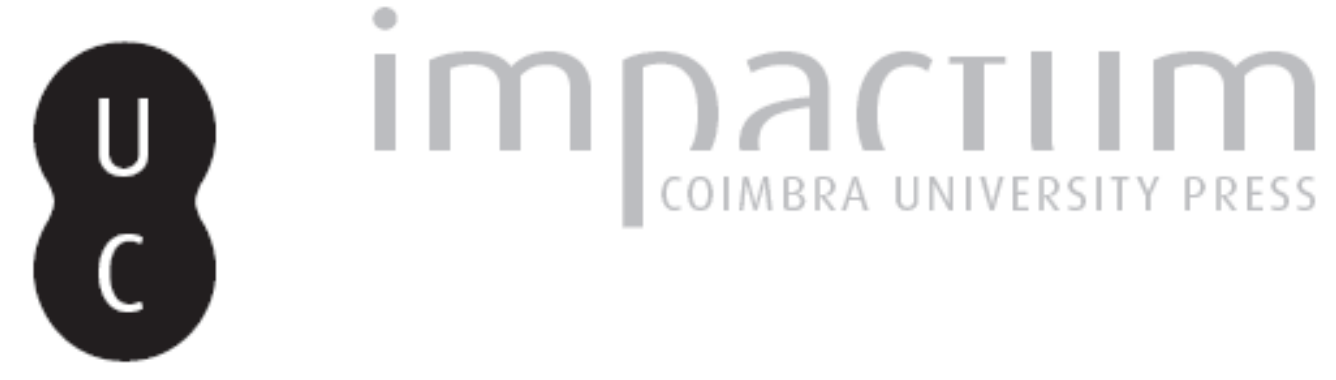
[Recensão a] Carine Bouthevillan, Gilles Dufrénot, Philipp e Frouté e Laurent Paul-
Les politiques budgétaires dans la crise: comprendre les enjeux actuels et les défis
futurs

Autor(es): $\quad$ Lavouras, Maria Matilde

Publicado por: Faculdade de Direito da Universidade de Coimbra

URL

persistente:

URI:http://hdl.handle.net/10316.2/35533

DOI: DOI:http://dx.doi.org/10.14195/0870-4260_56_8

Accessed : $\quad$ 26-Apr-2023 11:54:55

A navegação consulta e descarregamento dos títulos inseridos nas Bibliotecas Digitais UC Digitalis, UC Pombalina e UC Impactum, pressupõem a aceitação plena e sem reservas dos Termos e Condições de Uso destas Bibliotecas Digitais, disponíveis em https://digitalis.uc.pt/pt-pt/termos.

Conforme exposto nos referidos Termos e Condições de Uso, o descarregamento de títulos de acesso restrito requer uma licença válida de autorização devendo o utilizador aceder ao(s) documento(s) a partir de um endereço de IP da instituição detentora da supramencionada licença.

Ao utilizador é apenas permitido o descarregamento para uso pessoal, pelo que o emprego do(s) título(s) descarregado(s) para outro fim, designadamente comercial, carece de autorização do respetivo autor ou editor da obra.

Na medida em que todas as obras da UC Digitalis se encontram protegidas pelo Código do Direito de Autor e Direitos Conexos e demais legislação aplicável, toda a cópia, parcial ou total, deste documento, nos casos em que é legalmente admitida, deverá conter ou fazer-se acompanhar por este aviso. 


\section{UNIVERSIDADE DE COIMBRA}

FACULDADE DE DIREITO

\section{BOLETII DE CIÊECIAS ECONÓMICAS}

VOLUME LVI

$\begin{array}{llll}2 & 0 & 1 & 3\end{array}$

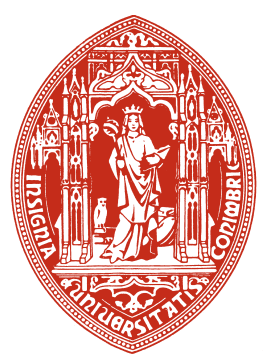

COIMBRA 


\section{Recensão}

Carine Bouthevillan, Gilles Dufrénot, Philippe Frouté e LAURent PAUL - Les politiques budgétaires dans la crise: comprendre les enjeux actuels et les défis futurs. Bruxelas: De Boeck, 2013. 353 p. ISBN 978-2804176747.

A obra Les politiques budgétaires dans la crise: comprendre les enjeux actuels et les défis futurs conta com prefácio de Michel Bouvier que aborda temas de Finanças Públicas de extrema actualidade.

Logo nas primeiras páginas o leitor é alertado para a problemática a ser abordada, nomeadamente para a importância que as questões a tratar ao longo das duas partes e 6 capítulos têm no contexto económico e em que a análise das políticas orçamentais em tempo de crise, sobretudo no contexto actual, ocupa um lugar central. A reflexão em torno daquelas políticas que é proposta alicerça-se em argumentos de ordem teórica exigidos pela complexidade das questões abordadas. Por outro lado, a diversidade de opiniões que contrapõe os defensores da intervenção estadual na economia e aqueles a que a esta se opõem - usualmente reconduzida à dicotomia entre pensamento liberal e pensamento keynesiano - aparece agora revestida de novos argumentos, decorrentes precisamente da incerteza sobre os efeitos que a intervenção do estado ou a sua falta possam gerar a nível económico, social e institucional. A esta cisão junta-se uma outra: a dos defensores da soberania orçamental dos estados e a dos defensores do federalismo da União Europeia, com perda de autonomia orçamental por parte dos Estados-membros.

Apesar da complexidade das questões, a abordagem seguida permite a um leque de destinatários alargado a leitura e compre- 
ensão das temáticas tratadas, centrando-se maioritariamente nas consequências da actividade financeira dos estados e dos demais actores económicos, com especial enfoque na necessidade de reconhecimento quase imediato e constante das mutações da realidade económica. São estas alterações que mais entraves colocam à tomada de decisões que leva à implementação de medidas inseridas nas políticas financeiras. Às dificuldades na antecipação dos comportamentos dos agentes económicos junta-se a complexidade das questões abordadas já referida, e que se adensa ainda mais com a incerteza relativa aos efeitos das medidas orçamentais. Por último é ainda necessário tomar em consideração uma das consequências da crise actual no domínio das finanças públicas: a tradicional análise separada das políticas orçamentais, políticas financeiras e da política monetária perde actualidade e reclama, ao invés, a consideração, análise e implementação de mediadas conjuntas, colocando em evidência o papel desempenhado pelo mercado financeiro na actual crise e da relação entre o endividamento excessivo e o desempenho do sector bancário.

As políticas a implementar deverão permitir obter um tríplice benefício: estabilidade monetária, estabilidade financeira e sustentabilidade das finanças públicas o que nos impele a referir que apenas um modelo que tome em consideração estes três objectivos e os pondere conjuntamente se poderá ter por ajustado à actual realidade.

Apontada por muitos como uma crise do mercado financeiro que se comunicou ao domínio das finanças públicas, a crise actual tem estado na origem de uma profusão de estudos muitas vezes inconclusivos porquanto se identifica o facto que esteve na origem do 'efeito dominó' mas não em que se torna possível encontrar a fórmula adequada para o suster. Não raras vezes encontramos noutros locais que não nesta obra a tendência para uma análise desligada dos modelos económicos e dos argumentos teóricos caindo numa mera análise factual. Aqui, ao invés, é feita uma análise factual sem descurar a necessária remissão e consideração dos argumentos teóricos por detrás de cada raciocínio.

Na primeira parte é feita uma análise macroeconómica e fiscal das implicações das políticas orçamentais. A análise que nos é proposta centra-se na importância e nas relações que esta política 
tem com as demais, sobretudo os efeitos e interdependências que decorrem para o comportamento das variáveis macroeconómicas e das variáveis financeiras. Na segunda parte é proposta ao leitor uma reflexão em torno da questão da governação e estabilidade financeira centrando-se na importância da política orçamental dentro da política macroeconómica e, sobretudo, da necessidade de aprofundamento da eficácia da política orçamental num quadro económico renovado e que considera as interacções existentes entre as políticas de finanças públicas e a estabilidade financeira.

Ao longo dos três capítulos em que se divide a parte primeira os autores procuram desmistificar os argumentos teóricos em torno da eficácia da política orçamental como: mecanismo de combate e saída das crises (Parte 1, capítulo 1), instrumento de crescimento a longo prazo (Parte 1, capítulo 2) e a fiscalidade em tempos de crise: a relação entre consolidação orçamental e crescimento (Parte 1, capítulo 3).

Na parte segunda que se subdivide também em três capítulos trata-se das questões relacionadas com o desempenho dos países da zona euro num quadro institucional que conjuga a existência de países com sem soberania orçamental e daqueles países que verdadeiramente perderam esta autonomia em virtude do programa de ajustamento económico e financeiro a que se encontram vinculados (Parte 2, capítulo 4), as interacções entre política orçamental e estabilidade financeira (Parte 2, capítulo 5) e por fim, o modelo óptimo de financiamento das dívidas públicas (Parte 2, capítulo 6).

A imposição de uma análise global dos impactos da política orçamental sobre a economia e que tome em consideração não apenas os fundamentos tradicionais como também os desenvolvimentos que decorrem do desenvolvimento das teorias clássicas e que tomam em consideração a mundialização da economia e a proliferação de novas realidades não reconduzíveis a modelos já anteriormente traçados. A conexão dos diversos fenómenos económicos aparece como evidência e impede a consideração isolada dos fenómenos orçamentais. A utilização do multiplicador orçamental como modelo que permite medir e justificar a adopção de determinada política orçamental encontra no período e contexto actual dificuldades de aplicação. Estas são decorrentes das restrições que a teoria económica reconhece existirem ao multiplica- 
dor, como sejam as importações (ou as relações económicas com o exterior que impliquem uma fuga de capitais para o estrangeiro ou a aquisição de bens importados) decorrentes directamente da abertuda face ao exterior das economias como consequência directa da mundialização, mas também a imponderável reacção das empresas e agentes privados (incluindo as famílias) na antecipação de acontecimentos futuros com o necessário ajustamento de comportamentos racionais do ponto de vista económico e, por último, o comportamento do sistema financeiro. Por outro lado, nos casos em que o multiplicador seja inferior a 1 ou nulo as políticas orçamentais de crescimento podem revelar-se ineficazes e colocar em causa o crescimento económico devido ao risco de um surto inflacionista. As dificuldades de utilização do multiplicador reconduzem-se à impossibilidade prática de antecipação dos comportamentos e da capacidade de agregação de informação que leva à coexistência de vários modelos de multiplicador: a cada tipo de imposto e a cada tipo de despesa corresponde um modelo diverso que permita considerar todas as especificidades a que correspondem diversos efeitos visíveis ao nível do período do multiplicador quer no curto quer no longo prazo. Estas e outras especificidades decorrentes da utilização dos multiplicadores orçamentais explicam as razões por detrás da impossibilidade de determinação ex ante da eficácia de políticas de crescimento e relançamento económico. A avaliação dos efeitos das políticas orçamentais apenas é possível a posteriori e mesmo assim considerando as margens de cálculo do saldo orçamental ajustado ao ciclo económico. O debate em torno da utilidade do cálculo dos multiplicadores orçamentais adensa-se com os novos argumentos e com as exigências da crise.

Uma outra consequência da crise é precisamente o facto de ter tornado clara a necessidade de reflexão em torno dos objectivos das políticas monetária e orçamental. O entendimento clássico de acordo com o qual a primeira se encontra relacionada com o controlo da estabilidade dos preços e a segunda é utilizada com a finalidade de manutenção da estabilização conjuntural tem sido questionada e encontra-se em fase de superação. Paradoxalmente parece existir actualmente uma inversão de objectivos e que implicou que no actual contexto de crise a taxa de juro indexante 
tenha descido a níveis mínimos em termos históricos e próximos de zero.

$\mathrm{Na}$ política monetária a crise impôs aos bancos centrais a adopção de medidas denominadas por 'não convencionais' com o objectivo de aumentar a liquidez bancária e que permitiram recolher fundos para serem posteriormente disponibilizados pelo sector bancário para investimento. Estas e outras medidas de políticas orçamentais não convencionais apenas parecem ser de admitir quando as demais medidas se revelem incapazes de atingir os objectivos a que se propunham, não se estranhando que o recurso a estas políticas seja ainda alvo de controversa discussão.

A longo prazo os objectivos das políticas orçamentais expandem-se e, para além da consolidação orçamental, encontramos ainda o reforço do crescimento económico. Contudo, no actual contexto também estes objectivos se encontram entraves decorrentes do actual contexto podendo mesmo questionar-se se não sofreram alterações.

Para finalizar a primeira parte refere-se no capítulo terceiro a relação entre a política fiscal em tempos de crise, a estabilidade orçamental e o crescimento económico. A eficácia e neutralidade que usualmente os liberais exigem dos sistemas fiscais devem ser temperados por considerações de inspiração nas teorias intervencionistas relacionadas precisamente com questões de equidade, redistribuição e desincentivo à prática de determinado comportamento.

A modelação da política fiscal haverá de ter em consideração todas as exigências e é do equilíbrio entre esta diversidade que será possível encontrar um ponto de equilíbrio tido por ideal em termos económicos. Tendo em consideração que o principal objectivo da tributação é a arrecadação de receitas para financiamento dos agenda estaduais, importa garantir que este é eficaz para o cumprir. Independentemente de outras considerações importa desenhar um sistema fiscal que seja consentido pelos contribuintes e adequado à capacidade contributiva. Para tanto o sistema há-de ser composto por impostos justos, calculado tendo por base regras simples, importar baixos custos de cobrança e que minimize os efeitos de fuga fiscal (evasão fiscal ou fraude). 
Convém tomar em consideração no desenho do imposto a determinação da base de incidência e os efeitos de distorção que este pode introduzir, nomeadamente a repercussão fiscal por forma a evitar o efeito de distorção. Importa considerar ainda a possibilidade de adopção de medidas fiscais com finalidade de orientação de comportamentos por forma a que estes levem ao efeito desejado. Ao invés da neutralidade propugnada pelos liberais a aproximação pigouviana parece permitir a intervenção pública para corrigir as falhas de mercado que levam a tomadas de decisão individuais de sub-óptimos (assimetrias de informação, externalidades ou situações de poder de mercado).

Esta possibilidade que era usualmente utilizada para justificar a criação de impostos com finalidades extrafiscais que se reconduziam ao refreamento de determinados comportamentos aparece no contexto actual como sustentáculo da adopção de medidas fiscais que orientem comportamentos privados no sentido tido por socialmente mais desejável. A questão coloca-se agora ao nível dos custos marginais privados e sociais e a partir daí determinar o nível óptimo da correcção a introduzir.

Com um objectivo similar é defensável a adopção de medidas fiscais de atracção de investimento estrangeiro, aproveitando a abertura actual dos mercados e que nem sempre tem que ser levada a cabo pelo sistema fiscal em sentido estrito, isto é, reflectida de qualquer modo no desenho deste. É também possível atingir o mesmo objectivo de forma directa através da concorrência fiscal mas também através daquela estratégia denominada por Tiebout e Oates como concorrência fiscal em bens públicos. Neste último caso não existiria alteração das normas fiscais mas a atracção do investimento estrangeiro decorreria do fornecimento de bens públicos adequados à atracção de fundos.

A par desta actuação mais alargada é ainda defensável uma actuação dirigida especificamente a uma determinada entidade e que decorre de negociações bilaterais. Todas estas actuações comportam riscos, sendo de salientar o mimetismo fiscal, decrescimento a longo prazo e redistribuição desigualitária e ineficaz da carga fiscal.

Para os que entendam que o sistema fiscal não deve ter apenas como objectivo a percepção de receitas e a neutralidade 
os problemas que se colocam levam a que se considerem ainda os efeitos da política fiscal sobre a redistribuição. Este objectivo assume-se no contexto actual como ambivalente e pode levar até a considerandos antagónicos: a opção por um determinado tipo de imposto pode revelar-se penalizadora dos rendimentos mais baixos e, não obstante a sua eficácia para a cobrança fiscal, mostra-se do ponto de vista da redistribuição desadequada. É o que sucede com o aumento da taxa de IVA cujos efeitos são explicáveis a partir da Curva de Laffer.

Às diversidades de políticas fiscais juntam os Autores as divergências entre os níveis de pressão fiscal. Estes, com a crise ao invés de diminuírem parecem ter aumentado. A mundialização das economias apenas pressionou a convergência (ou a aproximação) daqueles impostos que se mostrem mais capazes de influenciar a mobilidade dos factores de produção, bens e serviços.

A parte segunda inicia-se com o debate em torno da governance e das finanças públicas, centrando-se na questão da interacção entre estabilidade financeira e política orçamental para finalizar com a análise das formas de financiamento da dívida pública no actual contexto de crise económica.

As referências iniciais no capítulo quatro - o primeiro capítulo inserido na parte segunda - à problemática da governance relança a controvérsia das diferenciações dentro da União Europeia relativas aos países que façam parte da denominada zona euro e dos demais. São os primeiros que experienciam a existência de um quadro institucional que conjuga uma diversidade de quadros orçamentais decorrente, essa multiplicidade, da atribuição de competências aos estados-membros em termos de definição das políticas orçamentais, mas ao mesmo tempo balizada esta liberdade pela política monetária definida a nível central e que é idêntica para todos os países da zona euro.

É neste quadro institucional que a crise mostrou as fragilidades do sistema e limites da actual solução e que levaria à adopção de novas regras ao nível da União para suprir as lacunas reveladas pela crise e tendo como objectivo a coordenação das políticas económicas dos estados-membros e detecção atempada dos desequilíbrios económicos, sempre com a finalidade de promoção do crescimento e do emprego. 
As interacções entre a política orçamental e a estabilidade financeira, questão central no actual quadro económico. Percebeu-se que a dívida soberana não é um problema exclusivo das economias emergentes e que tal fenómeno pode ocorrer também noutras situações. De diverso o facto de nestas últimas se encontrar relacionada com a excessiva exposição ao risco do sistema bancário conjugado com a forte recessão económica (como sucedeu na Noruega, Suécia e Finlândia nos anos 90 e com o Japão a partir de 1997). Não foi a dívida soberana que esteve na origem destas crises mas a crise acabaria por conduzir a um aumento do endividamento público. Enquanto que os países nórdicos demoraram apenas alguns anos a superar a crise, o Japão mantém ainda um nível elevado de endividamento público mas conseguiu eliminar as consequências nefastas na economia.

Estes dois exemplos e os que se seguiriam permitiram concluir que são os países desenvolvidos quem se encontra no epicentro da crise actual, sem que seja possível limitar o efeito de contágio dada a existência de inúmeras ligações entre os diversos sistemas financeiros. Por outro lado, o crescimento da dívida pública aparece como um dos principais factores na origem da segunda fase da crise. Se inicialmente a crise económica aparece classificada como uma crise bancária típica, numa fase mais avançada - a partir do outono de 2008 - sofre uma mutação provocada pela conjugação da crise bancária e da crise económica que acabaria por conduzir em 2010 à crise das dívidas soberanas.

O novo contexto criado pela globalização parece ter conduzido a uma externalização para fora das fronteiras de cada estado dos ganhos económicos em contexto de crise e uma internalização das perdas. Por outro lado as soluções clássicas utilizadas nestes casos, como sejam o reforço do sistema bancário, ficam dificultadas devido aos montantes envolvidos (medidos estes em percentagem do PIB). Paralelamente as receitas utilizadas (desvalorização monetária e programa de ajustamento) não são suficientes no momento actual, dado que as consequências do default de um estado de uma pequena economia pode revelar-se catastrófico para a estabilidade financeira. Em realidade assistimos a um encontro de forças de dois actores: os estados e as instituições financeiras. Os estados necessitam daquelas para poderem continuar a financiar- 
-se e as instituições financeiras necessitam continuar a financiar os estados para evitarem cair elas mesmas numa situação de incumprimento que as levaria à falência. Este ciclo vicioso de relações (denominada pelos autores de "boucle infernale" (vicious loop)) está na origem das dificuldades aumentadas de saída da crise. Mostra-se contudo essencial a manutenção deste relacionamento por forma a evitar a transformação desta crise numa crise financeira de natureza sistémica em que a economia se precipitaria caso esta dependência cessasse abruptamente.

O impacto das crises financeiras sobre as finanças públicas decorre directamente da existência de custos directos relacionados com os planos públicos de resgate parciais ou totais das instituições financeiras e para os quais é necessário encontrar financiamento mas também dos custos indirectos relacionados com a degradação da sanidade financeira do próprio sistema. Enquanto que os primeiros são fáceis de mensurar os segundos são de dificil estimativa.

É neste quadro e intricadas relações entre a crise financeira e a crise da dívida soberana que terão de ser encontradas as soluções. A análise separada de ambas não mais é possível por se tratar de duas faces da mesma moeda, necessitando de solucionar-se conjuntamente. A principal preocupação actual prende-se com a necessidade de manter o funcionamento normal do sistema financeiro (e nesta tarefa os estados-membros gozam de todo o apoio do Banco Central Europeu) ainda que tal represente um aumento de custos para o erário público. Esta solução apresenta-se perniciosa tal como é habitual nas soluções adoptadas em estados de urgência: se a crise for durável torna-se insustentável a longo prazo e desconhecem-se os efeitos no funcionamento de um mercado financeiro com manipulação por parte dos bancos centrais.

Coloca-se portanto a questão da determinação das formas de financiamento da dívida pública em contexto de crise. Questão esta tratada no capítulo seis da parte segunda. O financiamento da dívida junto do mercado financeiro relacionado com as necessidades crescentes de financiamento da actividade estadual e, no contexto da União Europeia encontra acolhimento nas normas do Tratado, como decorrência da necessidade de garantir a independência necessária para que o BCE possa assegurar a estabilidade dos preços e as demais condições para o cumprimento de 
tal objectivo. Esta nova forma de financiamento continua a impor aos Estados obrigações de controlo da despesa pública e do crescimento da dívida, ainda que limitada por considerações diversas daquelas que se impõem quando o financiamento é feito ou através de criação monetária ou de receitas provenientes de tributos. A preocupação transfere-se para o indicador de solvabilidade do estado em causa, o mesmo será dizer, para os níveis de risco tidos por aceitáveis para os mercados e esta prende-se com dois factores principais: o risco de liquidez e o risco de solvabilidade. Estes indicadores apesar de comuns às entidades privadas assumem-se no caso do devedor público como importantes, mas a diversidade de natureza das entidades envolvidas faz com que a interpretação e significado dos mesmos possa divergir. É de dificil cálculo sobretudo o último sendo consequentemente idêntica a dificuldade se coloca para a fixação de um nível a partir do qual o risco da dívida soberana é considerado preocupante.

Esta opção pelo financiamento junto dos mercados trouxe para o campo específico das Finanças Públicas problemas até então exclusivos do mercado, tornando os estados dependentes do julgamento dos mercados sobre a sua solvabilidade e risco de incumprimento. Esta tensão coloca novos desafios à política orçamental, sobretudo de financiamento mas que não deixam de se reflectir nas demais políticas, com retracção de volumes de despesas e tendencial aumento de receitas provenientes de impostos. $\mathrm{O}$ saneamento das finanças públicas não será porém possível através de soluções rápidas, exigindo antes um retorno lento a níveis de despesa e de receita equilibrados e em que o recurso ao endividamento represente uma pequena percentagem. A implementação de soluções não convencionais e de políticas de repressão financeira serve apenas o propósito de ganhar tempo para que possam ser tomadas as medidas orçamentais adequadas, dado que a perenização no tempo daqueloutras medidas poderia originar efeitos perversos. Estes efeitos não parecem ser contudo superiores aos riscos decorrentes da impossibilidade de financiamento dos estados no mercado financeiro. Perante uma impossibilidade deste tipo e mantendo-se aquela necessidade de financiamento não restaria outra solução que não fosse a de monetarização da dívida, com a possível consequência inflacionista daí decorrente ou a declara- 
ção de insolvência, também esta com as consequências nefastas já conhecidas.

A actual crise financeira na zona euro parece (re)colocar, para os Autores, a questão em torno das consequências da adopção de uma moeda única para um leque de países heterogéneos e com divergências consideráveis ao nível do desempenho económico. Apesar de terem sido adoptados atempadamente os mecanismos de correcção estes não funcionaram adequadamente o que implicaria em alguns casos a necessidade de intervenção de entidades externas à União Europeia, falhadas que foram as medidas adoptadas pelo BCE desde 2008, e da implementação de programas de assistência financeira como mecanismos para resolução da crise.

Maria Matilde Lavouras

Faculdade de Direito da Universidade de Coimbra 